\title{
Ambulatory Surgical Facility
}

National Cancer Institute

\section{Source}

National Cancer Institute. Ambulatory Surgical Facility. NCI Thesaurus. Code C51945.

A publicly or privately owned institution which is primarily established and licensed for the purpose of providing elective surgical treatment of outpatients whose recovery, under normal and routine circumstances, will not require inpatient care. Such facility as herein defined does not include the offices of private physicians or dentists whether practicing individually or in groups. 